\title{
Oralidad ashaninka del río Perené
}

\author{
Rommel Plasencia Soto \\ rplasencia@hotmail.com \\ Melisa Sánchez Vásquez \\ meliantropo@hotmail.com
}

\begin{abstract}
Resumen
La memoria indígena de los pueblos amazónicos del Perú de hoy, es mostrada en cuatro relatos registrados en la comunidad de Mariscal Cáceres en el valle del río Perené de la selva central peruana.
\end{abstract}

Palabras clave: Oralidad, Amazonía peruana, ashaninkas

\begin{abstract}
The native memory in the villages amazonics of the Peru today is four oral narratives to pick in to the community of Mariscal Caceres of valley the Perene river in the jungle central Peruvian.
\end{abstract}

Key words: Orality, Peruvian jungle, ashaninkas

La recopilación del orbe narrativo ashaninka ha estado básicamente incluida en textos monográficos sobre su cultura como lo hicieran Weiss (1975) o Rojas (1994), o tratada puntualmente para indicar algunas referencias sobre su mundo mítico o sus peculiaridades lingüísticas. En esta última tendencia tenemos los trabajos de Anderson $(1985,1986)$, Fernández (1987) y Vílchez (s/f).

La lingüista Elsa Vílchez, por ejemplo, clasifica la tradición oral de este pueblo en tradiciones de origen, tradiciones de transformación, que son básicamente la zooformización de aquellos individuos o grupos que han transgredido normas ejemplares -como el de retener las mujeres o los alimentos-y las tradiciones de Avireri, travieso y ambiguo, que compone el mundo. Avireri, héroe cultural asháninka, a quien en los relatos se le presenta como un transformador de enemigos como los blancos o serranos, en moles de piedra, cae en una trampa preparada por su hermana y su cuñado, y luego es confinado al submundo fluvial, al igual que Pachakama, se enraíza en el suelo, ayudando a sostener el mundo. El río que aparece al final del mundo es el alto Perené. 
El conjunto arahuaco de los ashaninka del piedemonte amazónico comparten básicamente en el departamento de Junín, los territorios adyacentes a los ríos Perené, Ene, Tambo y Mantaro, que van a parar todos a la hoya del Amazonas.

Antropólogos como Weiss (2005) sostienen que este gran conjunto es en realidad uno solo, pero que sus particularidades regionales han sido descritas muchas veces por misioneros y lingüistas, como pueblos diferentes.

Así narra, por ejemplo, que las comunidades ubicadas en la zona de Pangoa en el sur-este del departamento de Junín, son denominadas como nomatsinguenga, cuando en realidad forman parte de la misma sociedad matsinguenga; solo que variados por la diferenciación regional y la auto-denominación.

Obviando la denominación general de "campas" que habían usado los franciscanos, y que Weiss (2005:6-7) sostiene como el más apropiado, a falta de otro etnónimo que los englobe, los pueblos pertenecientes a este grupo etnolingüístico "comparten un corpus de mitos comunes y una concepción sacralizada del espacio" (Santos y Barclay 2005: XXVI).

Este importante grupo etnolingüístico del piedemonte amazónico puede ser distinguido por su ocupación territorial en los ashaninkas del Perené, del Pichis, del Gran Pajonal y del Ucayali, que involucra aproximadamente diez mil personas y tres departamentos.

En su cosmología, el territorio ashaninka fue modelado en un tiempo mítico por diversas divinidades y héroes, como por ejemplo Avireri. La laguna donde emergió esta deidad ambivalente -creadora y caótica- está ubicada en la comunidad de Mariscal Cáceres, en el distrito de Perené, en la provincia de Chanchamayo.

Modelado y creado el paisaje con los seres vivientes de su territorio, son hoy referencia mítica y geográfica. Al igual que Renard-Casevitz (1988) quien hizo un interesante trabajo sobre la relación entre los mitos y el paisaje sagrado de los matsinguenga del río Urubamba en el departamento de Cusco.

No olvidemos, además, que una vez rota la resistencia indígena a la penetración criolla y mestiza a la región, la esfera y los contactos mercantiles se intensificaron irreversiblemente desde el siglo XIX, poniendo fin hoy a la autosuficiencia del pueblo asháaninka.

La coherencia en sus creencias, no obstante las diferencias regionales, se debe quizás a que las aldeas ashaninka están en un permanente proceso de fusión y fraccionamiento. Lógica pautada por mecanismos sociológicos plenamente comprensibles: la prescripción de elegir esposa (iinantsi) fuera de la aldea genera un espacio social extendido (Rojas 1994: 91-93), encadenada a una red si bien exogámica localmente, vista desde una perspectiva más amplia, se convierte en una suerte de endogamia regional que suelda una identidad étnica.

Por eso se dice que pueblos principales de la región como Marankiari o Pucharini son "principales" y "fundadores" de aldeas como Platanillo o Shimaki, para citar algunos casos. En esa cadena de pueblos, los eslabones muchas veces son los “ayómpari”, colaboradores, amigos y futuros parientes afines. ${ }^{1}$

\section{Los antiguos adoraban la candela}

«Los antiguos adoraban a la candela, mis abuelos contaban que ellos juntaban toda la leña y formaban una fogata, daban vuelta sobre la fogata, y la ceniza que quedaba se amontonaba como si se formara un cerro en una casa especial. Un día, mi mamá Lea

1 Estos relatos fueron recogidos de la señora Nancy Ruiz Mishari y de Juan Núñez, pobladores de la comunidad de Mariscal Cáceres en julio de 2008 en el marco de un programa de investigación más amplio. 
Michari empezó a jugar como todos los niños, la abuelita les decía no jueguen en la ceniza les va a pasar algo pero ellos como todos los niños traviesos seguían jugando, hasta que mi tía Eulogia se cayó y mi mamá empezó a reírse, la abuela les dijo no jueguen en las cenizas porque sus abuelos adoraban al fuego. Allí la resondraron para que no jugara en ese lugar, mi mamá se empezó a reír porque salió toda empolvada».

\section{Kishtariki}

«Mi abuelo Manuel Michari cuando llegó a Mariscal Cáceres agarró todos los terrenos del inca, él era el dueño y es uno de los fundadores de la comunidad. Vinieron poco a poco los colonos de peones como el señor Cornelio, como mi abuelo era bueno, él tenía cultivos, chacras de yuca y plátanos.

Antes todo era monte virgen, alli no más cazaban venados y paujiles, en ese cerro frente a Mariscal Cáceres que ahora está lleno de piñas.

Mi mamá me cuenta cuando era de mañana o en el atardecer, la zona se envolvía de nubes, y empezaba a gritar el tigre. Cuenta mi mamá que en las tardes venía a gritar el tigre y como tenían ganado, venía a comer el ganado. Las vacas empezaban a correr y los ashaninkas empezaban a espantar. En la mañana el tigre se peinaba, le llamaban kishtariki.

Por eso, antes la comunidad de Mariscal Cáceres se llamaba Kishtariki, que significa tigre que se peinaba y ellos veían como se peinaba el tigre, y cuenta mi abuelita que tanto daño hacía el tigre que lo mataron».

\section{En el cerro hay una campana}

"En el cerro hay una campana, mi abuelita me contaba que habian ollas enteradas nos cuenta que en el cerro Palmatambo es un cerro, que si divisas hacia atrás; allí hacían ollas, donde está el Joselito. Me contaron que los gringos venían a buscar ollas enteradas de oro, me imagino que habrán sacado. Como nosotros no sabíamos, no nos importaba pero se dieron cuenta que había señores que venian a escarbar, no sabemos si habrán sacado. En la espalda del panteón, mi mamá cuenta que habían enterradas ollas, que ellos no tomaban importancia, que por eso es que los colonos agarraron esa parte, eran ollas de oro, hachas, a nosotros no nos importaba pues solo vivíamos allí, y nos dedicábamos a la chacra en la comunidad de Mariscal Cáceres».

\section{El tesoro de Joselito}

«Acá había un horno (ahora es el panteón de la comunidad nativa Mariscal Cáceres), de alli han elaborado herramientas de trabajo. De los túneles de alli sacaban los materiales para poder curtir el cuero, los minerales para fundir. En ese horno está enterrado el Joselito (colono), allí a él lo han enterrado con todas sus riquezas. Antes hubo una guerra entre los colonos y los nativos, una guerra por sus terrenos (los de Joselito). Joselito es tarmeño, era un niñito, los nativos lo agarraron como un rehén, él creció entre nosotros, la familia ashaninka. Creció y comenzó hablar en nuestro idioma. Llegó a mandar como jefe de los ashaninkas, tuvo su familia. Hasta ahora lo vienen a ver y no lo hallan.

Vienen gente de afuera, los buscadores de tesoros han dejado varios huecos, porque Joselito se enterró con sus riquezas. En otro sector hay un túnel, han sacado vasitos, toritos, elaborados con piedritas. Ahora alli hay una escuelita, en el sector de Pampa Inca. 
El horno que funde las herramientas, él es quien ha enseñado a la comunidad hacer ese trabajo y hacian trueque, le daban pescado y yucas por una herramienta. Y esas herramientas se ven en la campana de la iglesia en La Merced, y de aquí la han sacado, del horno nuestro».

\section{A modo de interpretación}

El primer texto recuerda la importancia del fuego, que es un patrón general en los pueblos amazónicos. Siguiendo a Lévi-Strauss en su análisis estructural de los mitos (1968), se trataría de un código culinario; en la que el fuego establece el límite universal entre la naturaleza y la cultura. El fuego otorgado por una divinidad no solo coce la carne cazada, sino que establece una división elemental del trabajo, pues la que cocina es la esposa, que a su vez revela el principio de la organización social:

\section{Caza: Carne: Esposa: Fogón}

El segundo texto rememora los orígenes de la comunidad. Pueblo denso e itinerante, cada nueva aldea no sólo es la expresión de la fusión social sino también de la domesticación de la naturaleza. El tigre no sólo expresa esa esfera a-social sino paradójicamente también, la reiteración de los lazos sociales de la aldea con el supermundo, pues el jaguar está relacionado con la visión del sheripiari, el chamán consumidor de tabaco.

Los dos últimos textos son narraciones sincréticas, pues combinan algunos principios elementales de la sociedad ashaninka con las contingencias históricas. Están referidos a la relación entre el mundo ashaninka y el mundo exterior. No olvidemos que el mito no sólo es un modo de comunicación, sino también nos remite a relaciones básicas y que muchas de ellas tienes que ver con necesidades pragmáticas de una sociedad con su ambiente o con otras sociedades en la que el intercambio ocupa un lugar esencial, Joselito es un curioso personaje andino, que por su estatus de foraneidad quizás albergaba poderes, poseía "kánetsa", espíritu benefactor.

En el pensamiento mágico cuanto más desconocido es un personaje, mejor se adapta a que el grupo se inscriba en ella, sus códigos más representativos. Asimismo no es un misterio que con el auge de la colonización de fines del siglo XIX, muchos colonos saquearon y depredaron muchos monumentos, restos y signos materiales ashaninka, y que nos merece otro mito occidental: los indios guardan secretos y riquezas, que es preciso descubrir:

\section{Inframundo: Incas: Oro: Poder}

La destrucción de Metraro, donde según la tradición Ashaninka reposaban los restos de Santos Atahualpa, es más que elocuente. ${ }^{2}$ Metraro fue la residencia también del líder mesiánico en el siglo XVIII, y está ubicado en la naciente del pequeño río Nazaretequi, equidistante de los poblados de Santa Ana y Pichanaki. Antiguamente era centro de peregrinación de los pueblos indígenas de la zona, hasta que las autoridades de Tarma en 1890 , destruyeron y dispersaron sus restos.

Respecto a los hornos, se refiere a los cambios tecnológicos introducidos por los franciscanos desde el siglo XVIII. Se trataba de herrerías y fraguas que tenían por objeto fabricar y arreglar las herramientas de metal que los franciscano proveyeron. Rojas (1994) ha llamado a estos cambios como sinónimos de "mecanismos de dominación". Las herrerías no sólo permitieron a los misioneros blancos adscribir a la población nativa a sus fueros ganándolos para un orden ajeno a ellos, sino también para la dependencia tecnológica.

2 Podemos señalar las formaciones pétreas sagradas de Pahua Yompiri y Patsiri en la vecina comunidad de San Jerónimo. 
El hierro no sólo significó una mayor eficacia en el usufructo de los recursos naturales sino también dotó de un nuevo signo a las incursiones intra-étnicas. Quizás con las armas de hierro -y de fuego- se reforzaron las fricciones entre los propios ashaninka.

Santos (1987) ha relatado cómo se han recreado los vestigios de estas antiguas herrerías y se han convertido hoy, en centros de veneración o lugares que poseen una importancia especial. Codificados y circunscritos, ofrecen signos del territorio ahora disturbado entre nativos y choris (serranos).

También llama la atención, el hecho que se atribuya al oro rescatado por el no-indígena, la fabricación de las campanas de la iglesia de La Merced, pequeña ciudad que es la capital de la provincia.

Pues esta narración es parecida a muchas leyendas andinas en donde el mítico oro inca aparece impregnado en las campanas de muchas iglesias (como por ejemplo, de la María Angola en la catedral del Cusco).

Ese oro, por ser de los incas, les dota no sólo de incuestionable valor, sino de gran poder y resistencia. Es lo que se llamaría una inversión simbólica: así como en el Yawar Fiesta, el toro de origen español es vencido por el cóndor andino; las campanas andinas católicas, le deben su majestuosidad y poderío al oro de los incas.

Simbolismo que subvierte la cotidiana subordinación indígena de los sectores criollos y mestizos.

De igual modo ocurre en la selva central. La memoria de hechos históricos imperturbables como la rebelión de Juan Santos, las levas caucheras, la conformación de una extensa propiedad de cerca de medio millón de hectáreas en el Perené, la llegada de los adventistas y el terremoto de 1947 - que desencadenó Pachacamac-, que asoló la selva central y quizás recientemente la violencia política (como lo exponen Fernández y Brown, 2001) van recomponiendo los principios básicos de su pensamiento mítico y utópico.

\section{Bibliografía}

ANDERSON, Ronald J.

1985 Cuentos folklóricos de los ashaninka. Tomo 1, Pucallpa: ILV.

1986 Cuentos folklóricos de los ashaninka. Tomo 2, Pucallpa: ILV.

FERNÁNDEZ, Eduardo

1987 Para que nuestra historia no se pierda. Lima: CIPA.

FERNÁNDEZ, Eduardo y Michael BROWN

2001 Guerra de sombras: la lucha por la utopía en la amazonía peruana. Lima: CAAP/ Centro Argentino de Etnología Americana.

\section{LÉVI-STRAUSS}

1968 Lo crudo y lo cocido. México: Fondo de Cultura Económica.

RENARD-CASEVITZ F.M. y O.DOLLFUS

1988 "Geografía de algunos mitos y creencias: espacios simbólicos y realidades geográficas de los machiguenga del Alto-Urubamba" en Amazonía peruana 16.

ROJAS SOLEZZI, Enrique

1994 Los ashaninka, un pueblo tras el bosque. Lima: PUCP.

SANTOS GRANERO, Fernando

1987 “Templos y herrerías: utopía y recreación cultural en la amazonía peruana” en Bulletin del IFEA (17) 2.

SANTOS GRANERO, Fernando y BARCLAY Federica

Guía etnográfica de la Alta Amazonía. Vol. V: Campa Ribereños Asheninka Balboa: Smithsonian Tropical Research Institute/IFEA, 2005:7-40. 
VILCHEZ, Elsa

La tradición oral entre los ashaninkas y los machingengas de la Amazonia peruana en www/isisbib.unmsm.edu.pe

WEISS, Gerald

1975 Campa cosmology. The world of a forest tribe in South America. Nueva York: American Museum of Natural History.

2005 "Los campa ribereños” en Santos y Barclay, Ibid: 5-78.

\section{ANEXO}

Adoraban a la candela, sus abuelos trataban de juntar toda la leña y formaban una fogata, daban vuelta sobre la fogata, la ceniza que quedaba se amontonaba como si se formara un cerro en una casa especial. Un día mi mamá Lea Michari empezó a jugar como todo niño, la abuelita decía no jueguen en la ceniza les va a pasar algo pero como toda niña traviesa seguía jugando, hasta que una niña se cayó y mi mamá empezó a reírse, la abuela dijo no jueguen en las cenizas porque sus abuelos adoraban al fuego es una parte que me contó mi mamá. En Mariscal Cáceres, en que parte se encontraba esa casa, donde está el estadio, la Iglesia allí estaba la casa donde guardaban las cenizas y esa casa sigue, ya no hace muchos años que no está fue en la época de mis abuelos no lo recuerdo en qué año nació tu abuelito, tu mamá si vio la casa, si porque la que se cayó fue mi tía Eulogia ahora ya no vive aquí, le pasó algo después que se cayó en las cenizas, allí la resondraron para que no jugara en ese lugar, mi mamá se empezó a reír por que salió toda empolvada, y no sabes porque esa casa la botaron. Porque empezaron a venir los colonos otra gente, armar la comunidad, porque mi abuelo cuando vino agarró todos los terrenos inca, él era el dueño como se llama tu abuelo Manuel Michari y él es uno de los fundadores de la comunidad, vinieron poco a poco los colonos como peones el Sr. Cornelio, como mi abuelo era bueno, pero tu abuelo es Asháninka, tu abuelo tenía cultivos, claro yuca, plátano como todo era monte virgen allí no más cazaban venados, paujil, en ese cerro frente a Mariscal que ahora está lleno de piña, mi mamá me cuenta cuando era de mañana o en el atardecer se envolvía de nubes, y empezaba a gritar el tigre, como se llama ese lugar, le decimos pajonal, me cuenta mi mamá que en las tardes venía a gritar el tigre como tenían ganado venía a comer el ganado, la vaca empezaba a correr y ellos empezaban a espantar, en la mañana el tigre se peinaba por eso le llamaban KISHTARIKI, que significa eso anteriormente Mariscal (Cáceres) se llamaba KISHTARIKI pero que significa tigre que se peinaba y veían cómo se peinaba el tigre, cuenta mi abuelita el nombre de Mariscal Cáceres no era sino, KISHTARIKI, tanto daño que hacía el tigre lo mataron, cuando mi abuelo agarró todo Pampa Inca ellos trabajan con la Peruvian, que es una empresa, cosechaban café todo lo de arriba era café de la Peruvian Corporation, después mi abuelo dijo mejor agarramos nuestra parcela, sin embargo ellos trabajan allí sembraban, criaban gallinas pero todos los productos que ellos tenían que ir a vender en Pampa Huari, que queda a más de un día en burro desde Mariscal Cáceres, no podían vender en otro lugar, llevaban gallina, frijoles, no podían vender a otra persona, solo a los gringos, poco a poco se dieron cuenta, a veces ellos les cambiaban, chafles que es machete, ollas, con otros productos que ellos necesitaban. Cuando no tenían sal se iban a Paucartambo, por donde es como quien se va a Villa Rica a pie se iba mi abuelito a pie caminaban días y días, sal para el ganado, para ellos. 